\title{
Perbandingan kadar gula darah pasca pembedahan dengan anestesia umum dan anestesia spinal
}

\author{
${ }^{1}$ Fabiola I. Lumanauw \\ ${ }^{2}$ Harold F. Tambajong \\ ${ }^{2}$ Barry I. Kambey
}

\author{
${ }^{1}$ Kandidat Skripsi Fakultas Kedokteran Universitas Sam Ratulangi Manado \\ ${ }^{2}$ Bagian Anestesiologi dan Terapi Intensif Fakultas Kedokteran Universitas Sam Ratulangi - \\ RSUP Prof. R. D. Kandou Manado \\ Email: lhalhafil@gmail.com
}

\begin{abstract}
Anesthesia and surgery could evoke stress response that can affect blood glucose levels. The purpose of this study is to compare the blood glucose levels after surgery with general anesthesia and spinal anesthesia. This was an analytic prospective observational research with cross-sectional design. Researched on 32 patients by consecutive random sampling who meet inclusion and exclusion criteria, then divided into two groups, namely the group undergoing surgery with general anesthesia and the group undergoing surgery with spinal anesthesia. Measurements of blood glucose levels was done in 1 hour before induction of premedication and 4 hours after surgery. The statistical analysis were done using Shapiro-Wilk Test to determine the normal distribution of samples, and independent t-test to compare blood glucose levels after surgery with general anesthesia and spinal anesthesia. The result showed there was significantly different between blood glucose levels after surgery with general anesthesia and spinal anesthesia ( $\mathrm{p}$-value $=0.006$ or $\mathrm{p}$ $<0.05$ ). Mean of blood glucose level after surgery in general and spinal anesthesia were 96 $\mathrm{mg} / \mathrm{dl}$ and 79,4 mg/dl. Conclusion: General anesthesia had more influence on the increase in blood glucose levels after surgery compared to spinal anesthesia.
\end{abstract}

Keywords: stress response, blood glucose levels, general anesthesia, spinal anesthesia

\begin{abstract}
Abstrak: Anestesia dan pembedahan akan menyebabkan timbulnya respon stres yang dapat mempengaruhi kadar gula darah. Penelitian ini bertujuan untuk mengetahui perbandingan kadar gula darah pasca pembedahan dengan anestesia umum dan anestesia spinal. Metode penelitian ini menggunakan desain observasional analitik prospektif dengan rancangan cross-sectional. Penelitian dilakukan terhadap 32 pasien yang didapatkan secara consecutive random sampling yang memenuhi kriteria inklusi dan eksklusi, lalu dibagi menjadi 2 kelompok, yaitu kelompok yang menjalani pembedahan dengan anestesia umum dan kelompok yang menjalani pembedahan dengan anestesia spinal. Pengukuran kadar gula darah dilakukan 2 kali, yaitu 1 jam sebelum induksi premedikasi dan 4 jam setelah pembedahan. Analisis statistik dilakukan dengan uji Shapiro-Wilk untuk mengetahui normalitas distribusi sampel, dan uji-t independen untuk membandingkan kadar gula darah pasca pembedahan dengan anestesia umum dan anestesia spinal. Hasil penelitian menunjukkan perbedaan yang bermakna antara kadar gula darah pasca pembedahan dengan anestesia umum dan anestesia spinal (nilai $\mathrm{p}=0,006$ atau $\mathrm{p}<0,05$ ). Rerata kadar gula darah pasca pembedahan dengan anestesia umum sebesar $96 \mathrm{mg} / \mathrm{dl}$, sedangkan pada anestesia spinal sebesar 79,4 mg/dl. Simpulan: Anestesia umum lebih berpengaruh terhadap peningkatan kadar gula darah pasca pembedahan dibandingkan dengan anestesia spinal.
\end{abstract}

Kata kunci : respon stres, kadar gula darah, anestesia umum, anestesia spinal 
Anestesia dan pembedahan dapat menyebabkan timbulnya respon stres. ${ }^{1}$ Respon stres merupakan suatu keadaan dimana terjadi perubahan fisiologis tubuh sebagai reaksi terhadap kerusakan jaringan yang ditimbulkan oleh keadaan-keadaan seperti anestesia, pembedahan, syok, dan infeksi. ${ }^{2}$ Perubahan fisiologis tubuh yang terjadi akibat respon stres terhadap anestesia dan pembedahan dapat menyebabkan aktivasi sistem saraf simpatis, perubahan hormonal dan metabolik sehingga meningkatkan sekresi hormon-hormon neuroendokrin yaitu katekolamin, aldosteron, kortisol, glukagon. Peningkatan glukoneogenesis karena meningkatnya sekresi kortisol, glukagon dan katekolamin menyebabkan terjadinya hiperglikemik. ${ }^{2-4}$

Anestesia umum adalah suatu keadaan tidak sadar yang bersifat sementara yang diikuti oleh hilangnya rasa nyeri diseluruh tubuh akibat pemberian obat anestesia. ${ }^{5}$ Pada saat pembedahan, anestesia umum yang sering digunakan adalah pemberian anestesia melalui intravena dan inhalasi untuk menunjang tindakan pembedahan yang adekuat. Tetapi anestesia umum tidak selalu menjadi pilihan. Hal ini tergantung pada keadaan klinis pasien. ${ }^{6}$

Anestesia umum tidak berpengaruh langsung terhadap perubahan-perubahan fisiologis dan metabolik yang akan terjadi sebagai respon terhadap stres, sehingga dapat meningkatakan sekresi kortisol dan menyebabkan peningkatan kadar gula darah. ${ }^{4}$

Anestesia spinal merupakan salah satu teknik anestesia regional yang dikenal lebih efektif dan sederhana untuk pembedahan pada daerah ekstremitas bawah, perineum dan inguinal dengan menyuntikkan obat anestetik lokal ke dalam ruang subaraknoid. ${ }^{7,8}$ Obat yang sering digunakan adalah bupivakain. Blokade saraf dengan anestesia regional berpengaruh langsung pada respon endokrin dan metabolik sehingga dapat menekan respon stres. Mekanisme dasar anestesia spinal yaitu menghambat sinyal nosiseptif mencapai sistem saraf pusat.
Penghambatan terjadi pada impuls saraf aferen dan eferen, dimana saraf aferen melepaskan hormon hipofisis yaitu hormon adrenokortikal dan pelepasan kortisol melalui impuls saraf eferen oleh adrenocorticotrophic hormone (ACTH). Blokade pada dermatom T4 ke S5 selama pembedahan pada perut dan ekstremitas bagian bawah dapat mencegah peningkatan kortisol. ${ }^{4}$

Bernadus JE, Witjaksono, dan Soenarjo ${ }^{9}$ dalam penelitiannya ditemukan perbedaan yang bermakna terhadap kadar gula darah pasca induksi anestesia umum antara pemberian etomidat $0,2 \mathrm{mg} / \mathrm{kgBB}$ dan propofol 2,5 $\mathrm{mg} / \mathrm{kgBB}$. Pada pemberian etomidat $0,2 \mathrm{mg} / \mathrm{kgBB} 2$ jam pasca induksi dapat menurunkan kadar gula darah namun kembali normal pada 8 jam pasca induksi, sedangkan pada pemberian propofol $2,5 \mathrm{mg} / \mathrm{kgBB}$ tidak menyebabkan penurunan kadar gula darah.

Penelitian Manafi A, dkk ${ }^{10}$ menunjukkan anestesia spinal lebih efektif untuk menurunkan kadar gula darah dan mengurangi efek merugikan pada pasien selama seksio sesarea daripada anestesia umum ( $\mathrm{p}=0,007)$. Rerata kadar gula darah setelah pembedahan dengan anestesia spinal 79,93 $\mathrm{mg} / \mathrm{dl}$, sedangkan pada anestesia umum $94,87 \mathrm{mg} / \mathrm{dl}$.

Pada tahun 2014, dalam penelitian terhadap pasien dengan diabetes maupun tidak dengan diabetes yang melakukan pembedahan transplantasi panggul yang tercantum dalam cermin dunia kedokteran, didapatkan hasil pemeriksaan kadar glukosa darah pada pasien yang mendapat anestesia umum signifikan lebih tinggi ( $\mathrm{p}<$ $0,05)$, sedangkan pasien yang mendapat anestesia spinal kadar glukosa darahnya tetap stabil. ${ }^{11}$

Dari hasil-hasil penelitian sebelumnya dan karena keterkaitan respon stres terhadap anestesia dan pembedahan dapat meningkatkan kadar gula darah, penulis merasa tertarik untuk membandingkan kadar gula darah pasca pembedahan dengan anestesia umum dan kadar gula darah pasca pembedahan dengan anestesia spinal di RSUP. Prof. R. D. Kandou Manado. 


\section{METODE PENELITIAN}

Penelitian ini bersifat observasional analitik prospektif menggunakan studi cross-sectional yang dilaksanakan di Instalasi Bedah Sentral (IBS) RSUP. Prof. R.D. Kandou Manado periode Oktober November 2016. Pemilihan sampel dilakukan dengan cara consecutive random sampling karena keterbatasan waktu penelitian. Penelitian ini melakukan pengukuran kadar gula darah sebanyak 2 kali, yaitu 1 jam sebelum induksi premedikasi dan 4 jam setelah pembedahan.

\section{HASIL PENELITIAN}

Berdasarkan penelitian yang telah dilakukan di IBS RSUP Prof. dr. R. D. Kandou Manado periode Oktober November 2016, didapatkan 32 pasien yang memenuhi kriteria inklusi dan eksklusi, yang dibagi dalam 2 kelompok, yaitu kelompok yang mendapat anestesia umum sebanyak 16 pasien dan yang mendapat anestesia spinal sebanyak 16 pasien.

\section{Karakteristik Subjek Penelitian}

Karakteristik subjek penelitian ini dibagi menjadi karakteristik umum dan karakteristik klinis, yang meliputi jenis kelamin, usia, indeks massa tubuh (IMT), jenis pembedahan dan durasi pembedahan pada pasien yang telah menjalani pembedahan dengan anestesia umum dan anestesia spinal. Tabel disajikan dalam frekuensi $(\%)$.

Pada Tabel 1 dijelaskan karakteristik pasien yang mendapat anestesia umum menurut jenis kelamin, terdiri dari 8 pasien laki-laki $(50 \%)$ dan 8 pasien perempuan $(50 \%)$, sedangkan yang mendapat anestesia spinal, terdiri dari 2 pasien laki-laki $(12,5 \%)$ dan 14 pasien perempuan $(87,5 \%)$. Berdasarkan usia, didapatkan subjek terbanyak yang menggunkan anestesia umum adalah pada rentang usia 18-25 tahun sebanyak 8 pasien (50\%), diikuti usia 26-35 tahun 6 pasien $(37,5 \%)$, dan usia 3645 tahun sebanyak 2 pasien $(12,5 \%)$, sedangkan subjek yang menggunakan anestesia spinal terbanyak pada rentang usia 26-35 tahun, yaitu 7 pasien $(43,8 \%)$, diikuti usia 18-25 tahun sebanyak 5 pasien (31,3\%), dan usia 26-45 tahun sebanyak 3 pasien $(18,8 \%)$, dan yang paling sedikit yaitu 1 pasien $(6,3 \%)$ pada usia $46-55$ tahun. Berdasarkan IMT, kelompok pasien dengan anestesia umum sebanyak 12 pasien (75\%) dengan IMT 18,5-24,99 dan 4 pasien (25\%) dengan IMT 25,00-29,99. Pada kelompok pasien dengan anestesia spinal sebanyak 8 pasien $(50 \%)$ dengan IMT $18,5-$ 24,99 dan 8 pasien $(50 \%)$ dengan IMT 25,00-29,99.

Tabel 1. Karakteristik Umum Subjek Penelitian

\begin{tabular}{ccc}
\hline Karakteristik & $\begin{array}{c}\text { Anestesia } \\
\text { Umum } \\
\text { n(\%) }\end{array}$ & $\begin{array}{c}\text { Anestesia } \\
\text { Spinal } \\
\mathbf{n}(\%)\end{array}$ \\
\hline Jenis Kelamin & & \\
Laki-Laki & $8(50 \%)$ & $2(12,5 \%)$ \\
Perempuan & $8(50 \%)$ & $14(87,5 \%)$ \\
Usia (tahun) & & \\
$18-25$ & $8(50 \%)$ & $5(31,3 \%)$ \\
$26-35$ & $6(37,5 \%)$ & $7(43,8 \%)$ \\
$36-45$ & $2(12,5 \%)$ & $3(18,8 \%)$ \\
$46-55$ & 0 & $1(6,3 \%)$ \\
IMT $\left(\mathrm{kg} / \mathrm{m}^{2}\right)$ & & \\
$18,50-24,99$ & $12(75 \%)$ & $8(50 \%)$ \\
$25,00-29,99$ & $4(25 \%)$ & $8(50 \%)$ \\
\hline
\end{tabular}

Pada Tabel 2 dijelaskan karakteristik subjek menurut jenis dan durasi pembedahan. Jenis pembedahan terbanyak yang menggunakan anestesia umum adalah bedah tulang, yakni sebanyak 6 pasien $(37,5 \%)$ dan paling sedikit yaitu kebidanan dan kandungan, bedah urologi, dan bedah digestif masing-masing sebanyak 1 pasien $(6,3 \%)$. Untuk jenis pembedahan terbanyak yang menggunakan anestesia spinal adalah kebidanan dan kandungan, yakni sebanyak 13 pasien $(81,2 \%)$ dan yang paling sedikit yaitu 1 pasien $(6,3 \%)$ jenis bedah urologi. Tidak didapatkan pasien bedah tumor, bedah digestif dan THT-KL yang yang menggunakan anestesia spinal. Berdasarkan durasi pembedahan, yaitu pembedahan dengan anestesia umum selama 60-90 menit sebanyak 9 pasien $(56,3 \%)$ dan selama 91-120 menit sebanyak 7 pasien $(43,8 \%)$, sedangkan 
pembedahan dengan anestesia spinal terbanyak pada durasi 60-90 menit yaitu 12 pasien $(75 \%)$ dan paling sedikit yaitu 1 pasien $(6,3 \%)$ pada durasi $<60$ menit.

Tabel 2. Karakteristik Klinis Subjek Penelitian

\begin{tabular}{ccc}
\hline Karakteristik & $\begin{array}{c}\text { Anestesia } \\
\text { Umum } \\
\text { n(\%) }\end{array}$ & $\begin{array}{c}\text { Anestesia } \\
\text { Spinal } \\
\mathbf{n ( \% )}\end{array}$ \\
\hline $\begin{array}{c}\text { Jenis Pembedahan } \\
\text { Kebidanan \& }\end{array}$ & $1(6,3 \%)$ & 13 \\
Kandungan & & $(81,2 \%)$ \\
Bedah Tulang & $6(37,5 \%)$ & $2(12,5 \%)$ \\
Bedah Urologi & $1(6,3 \%)$ & $1(6,3 \%)$ \\
Bedah Tumor & $4(25 \%)$ & 0 \\
Bedah Digestif & $1(6,3 \%)$ & 0 \\
THT-KL & $3(18,8 \%)$ & 0 \\
Durasi Pembedahan & & \\
< 60 menit & 0 & $1(6,3 \%)$ \\
60-90 menit & $9(56,3 \%)$ & $12(75 \%)$ \\
91-120 menit & $7(43,8 \%)$ & $3(18,7 \%)$ \\
\hline
\end{tabular}

\section{Hasil Pengukuran Kadar Gula Darah}

Pada penelitian ini dilakukan 2 kali pengukuran kadar gula darah dari masingmasing pasien, yaitu 1 jam sebelum induksi premedikasi dan 4 jam setelah pembedahan menggunakan alat Easy Touch GCU. Kadar gula darah yang diukur yaitu kadar gula darah arteriol. Nilai normal kadar gula darah yaitu 70-125 mg/dl. Jika kadar gula darah $<70 \mathrm{mg} / \mathrm{dl}$ termasuk kategori hipoglikemik dan jika kadar gula darah $\geq 126 \mathrm{mg} / \mathrm{dl}$ dapat dikatakan hiperglikemik

Tabel 3. Kadar Gula Darah 1 jam Sebelum Pembedahan

\begin{tabular}{ccc}
\hline $\begin{array}{c}\text { Kadar Gula } \\
\text { Darah }\end{array}$ & $\begin{array}{c}\text { Anestesia } \\
\text { Umum } \\
\text { n=16 }\end{array}$ & $\begin{array}{c}\text { Anestesia } \\
\text { Spinal } \\
\text { n=16 }\end{array}$ \\
\hline$<70 \mathrm{mg} / \mathrm{dl}$ & $2(12,5 \%)$ & $5(31,3 \%)$ \\
$70-125 \mathrm{mg} / \mathrm{dl}$ & $14(87,5 \%)$ & $11(68,8 \%)$ \\
$\geq 126 \mathrm{mg} / \mathrm{dl}$ & 0 & 0 \\
Total & $16(100 \%)$ & $16(100 \%)$ \\
\hline
\end{tabular}

Tabel 3 menjelaskan bahwa 2 pasien $(12,5 \%)$ dalam kelompok anestesia umum memiliki kadar gula darah dibawah normal $(<70 \mathrm{mg} / \mathrm{dl})$ dan 14 pasien $(87,5 \%)$ memiliki kadar gulah darah normal (70-125 $\mathrm{mg} / \mathrm{dl})$, sedangkan pada kelompok anestesia spinal 5 pasien $(31,3 \%)$ memiliki kadar gula darah dibawah normal $(<70$ $\mathrm{mg} / \mathrm{dl})$ dan 11 pasien $(68,8 \%)$ memiliki kadar gulah darah normal $(70-125 \mathrm{mg} / \mathrm{dl})$. Tidak terdapat pasien dengan kadar gula darah di atas normal ( $\geq 126 \mathrm{mg} / \mathrm{dl})$.

Tabel 4. Kadar Gula Darah 4 jam Setelah Pembedahan

\begin{tabular}{ccc}
\hline $\begin{array}{c}\text { Kadar Gula } \\
\text { Darah }\end{array}$ & $\begin{array}{c}\text { Anestesia } \\
\text { Umum } \\
\mathbf{n = 1 6}\end{array}$ & $\begin{array}{c}\text { Anestesia } \\
\text { Spinal } \\
\mathbf{n = 1 6}\end{array}$ \\
\hline$<70 \mathrm{mg} / \mathrm{dl}$ & $1(6,3 \%)$ & $2(12,5 \%)$ \\
$70-125 \mathrm{mg} / \mathrm{dl}$ & $15(93,7 \%)$ & $14(87,5 \%)$ \\
$\geq 126 \mathrm{mg} / \mathrm{dl}$ & 0 & 0 \\
Total & $16(100 \%)$ & $16(100 \%)$ \\
\hline
\end{tabular}

Pada Tabel 4 menjelaskan bahwa 1 pasien $(6,3 \%)$ dalam kelompok anestesia umum memiliki kadar gula darah dibawah normal $(<70 \mathrm{mg} / \mathrm{dl})$ dan 15 pasien $(93,7 \%)$ memiliki kadar gulah darah normal (70-125 $\mathrm{mg} / \mathrm{dl})$, sedangkan pada kelompok anestesia spinal 2 pasien $(12,5 \%)$ memiliki kadar gula darah dibawah normal $(<70$ $\mathrm{mg} / \mathrm{dl})$ dan 14 pasien $(87,5 \%)$ memiliki kadar gulah darah normal (70-125 mg/dl). Tidak terdapat pasien dengan kadar gula darah di atas normal ( $\geq 126 \mathrm{mg} / \mathrm{dl}$ ) (Gambar 1 dan 2).

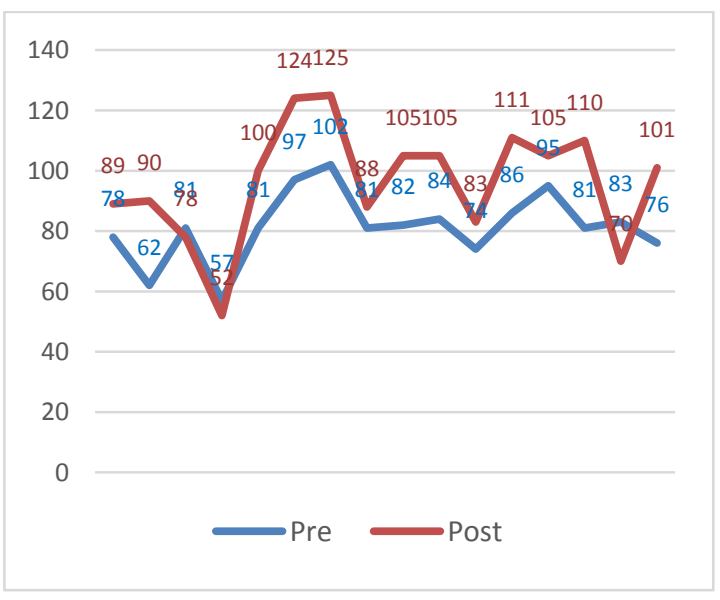

Gambar 1. Kadar Gula Darah 1 jam Sebelum dan 4 jam Setelah Pembedahan dengan Anestesia Umum 


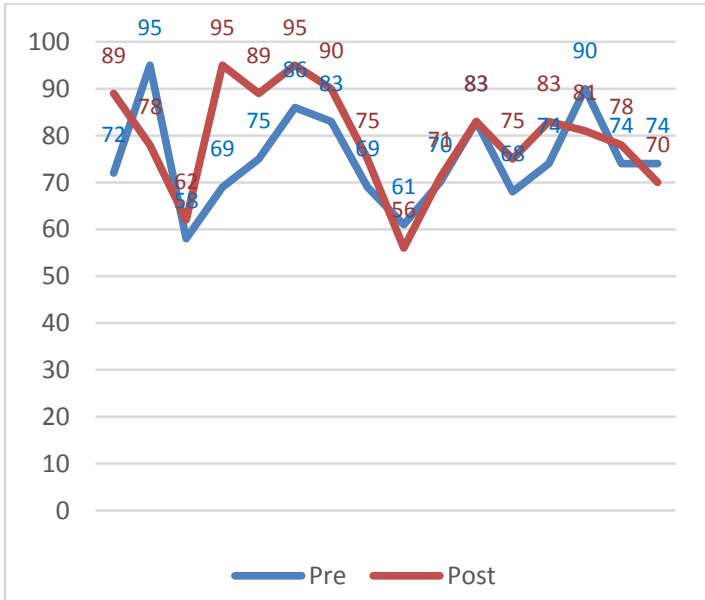

Gambar 2. Kadar Gula Darah 1 jam Sebelum dan 4 jam Setelah Pembedahan dengan Anestesia Spinal

Pada Tabel 5 menjelaskan bahwa 13 pasien $(81,3 \%)$ dalam kelompok anestesia umum mengalami peningkatan kadar gula darah dan 3 pasien $(18,8 \%)$ mengalami penurunan kadar gula darah, sedangkan 11 pasien $(68,8 \%)$ pada kelompok anestesia spinal mengalami peningkatan kadar gula darah, 4 pasien (25\%) mengalami penurunan kadar gula darah, dan 1 pasien $(6,3 \%)$ kadarnya tidak berubah dari sebelum dan sesudah pembedahan.

Tabel 5. Perubahan Kadar Gula Darah dari 1 jam Sebelum Pembedahan ke 4 jam Setelah Pembedahan

\begin{tabular}{ccc}
\hline $\begin{array}{c}\text { Perubahan } \\
\text { KGD }\end{array}$ & $\begin{array}{c}\text { Anestesia } \\
\text { Umum } \\
\mathbf{n = 1 6}\end{array}$ & $\begin{array}{c}\text { Anestesia } \\
\text { Spinal } \\
\mathbf{n = 1 6}\end{array}$ \\
\hline Meningkat & $13(81,3 \%)$ & $11(68,8 \%)$ \\
Menurun & $3(18,8 \%)$ & $4(25 \%)$ \\
Tidak berubah & 0 & $1(6,3 \%)$ \\
Total & $16(100 \%)$ & $16(100 \%)$ \\
\hline
\end{tabular}

Tabel 6 menjelaskan bahwa rerata kadar gula darah sebelum pembedahan dengan anestesia umum $81,3 \mathrm{mg} / \mathrm{dl}$ dan setelah pembedahan $96 \mathrm{mg} / \mathrm{dl}$, sedangkan rerata kadara gula darah sebelum pembedahan dengan anestesia spinal 75,1 $\mathrm{mg} / \mathrm{dl}$ dan setelah pembedahan 79,4 mg/dl. Uji normalitas Shapiro-Wilk mendapatkan nilai $\mathrm{p}>0,05$ baik anestesia umum maupun anestesia spinal (data terdistribusi normal).
Tabel 6. Data Deskriptif Sebelum dan Setelah Pembedahan Menggunakan Anestesia Umum dan Anestesia Spinal

\begin{tabular}{ccccc}
\hline $\begin{array}{c}\text { Jenis } \\
\text { Anestesia }\end{array}$ & KGD & Mean & Sd. & $\begin{array}{c}\text { Uji } \\
\text { Normalitas } \\
\text { SW }\end{array}$ \\
\hline Spinal & Pre & 75,1 & 10,1 & 0,258 \\
& Post & 79,4 & 11,1 & 0,661 \\
Umum & Pre & 81,3 & 11,4 & 0,653 \\
& Post & 96,0 & 19,3 & 0,661 \\
\hline
\end{tabular}

Karena data terdistribusi normal maka dilakukan uji-t untuk mengetahui pengaruh antara dua variabel, dalam hal ini proses perubahan kadar gula darah pada subjek penelitian sebelum dan setelah dilakukan pembedahan menggunakan anestesia umum dan anestesia spinal. Hasil penelitian mendapatkan anestesia umum lebih berpengaruh terhadap perubahan (peningkatan) kadar gula darah setelah pembedahan dibandingkan dengan anestesia spinal yang dibuktikan dengan uji $\mathrm{t}$-independen dengan nilai $\mathrm{p}$ untuk anestesia umum 0,000 ( $\mathrm{p}<0,05)$ sedangkan nilai $\mathrm{p}$ untuk anestesia spinal 0,116 ( $p>0,05)$.

Tabel 7. Perbandingan Anestesia Umum dan Anestesia Spinal Sebelum dan Setelah Pembedahan Terhadap Kadar Gula Darah

\begin{tabular}{|c|c|c|}
\hline Jenis Bedah & Proses Bedah & p value \\
\hline Umum & $\begin{array}{l}\text { Sebelum - } \\
\text { Setelah }\end{array}$ & 0,000 \\
\hline Spinal & $\begin{array}{l}\text { Sebelum - } \\
\text { Setelah }\end{array}$ & 0,116 \\
\hline
\end{tabular}

Tabel 8 dan Gambar 3 menjelaskan perbandingan antara anestesia umum dan anestesia spinal terhadap kadar gula darah bermakna karena nilai $\mathrm{p}=0,006$ atau $\mathrm{p}<$ 0,05 . Nilai $p$ dihitung berdasarkan uji-t independen.

Tabel 8. Perbandingan Anestesia Umum dan Anestesia Spinal Setelah Pembedahan

\begin{tabular}{ccc}
\hline $\begin{array}{c}\text { Jenis } \\
\text { Anestesia }\end{array}$ & $\begin{array}{c}\text { Proses } \\
\text { Bedah }\end{array}$ & p value \\
\hline Umum & Pasca Bedah & 0,006 \\
Spinal &
\end{tabular}




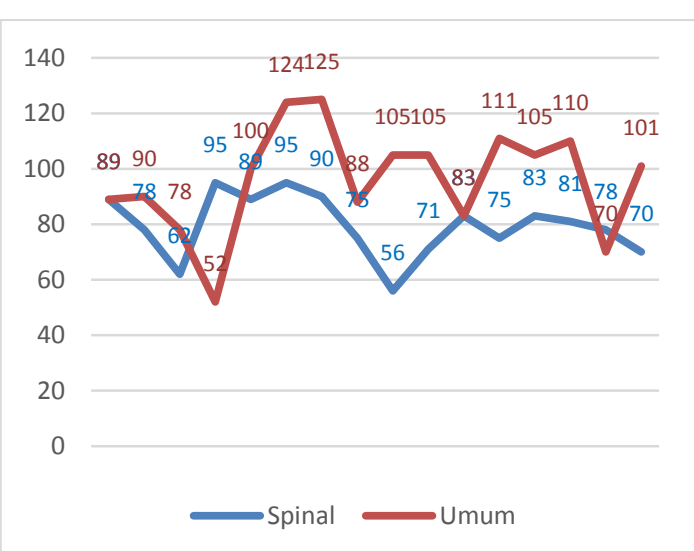

Gambar 3. Perbandingan Kadar Gula Darah 4 jam Setelah Pembedahan dengan Anestesia Umum dan Anestesia Spinal

\section{BAHASAN}

Pada setiap pasien yang akan menjalani tindakan pembedahan, respon stres akan muncul tergantung dari tingkat kecemasan, ketakutan, ataupun kesedihan pasien (stres psikologis) terhadap tindakan pembedahan, efek metabolik terhadap anestesia, dan bagaimana prosedur pembedahan yang akan dijalani. ${ }^{12}$ Tingkat kecemasan setiap pasien berbeda-beda. Begitu pula dengan perubahan hormonal yang terjadi di dalam tubuh manusia sebagai respon terhadap anestesia dan pembedahan sehingga memicu sekresi hormon kortisol yang merupakan hormon yang paling berpengaruh terhadap peningkatan kadar gula darah. ${ }^{\mathbf{2 , 4 3}}$ Selain kortisol, epinefrin merangsang pemecahan glikogen oleh hati, mengurangi penyerapan glukosa oleh otot-otot dan menghambat pelepasan insulin oleh pankreas. Akibatnya kadar gula darah akan meningkat. Disamping itu, jenis pembedahan serta durasi pembedahan juga turut memengaruhi peningkatan kadar gula darah. Tapi pada penelitian ini, peneliti membatasi durasi pembedahan yang tidak lebih dari 2 jam. ${ }^{12}$

Pada penelitian ini dapat dilihat perubahan kadar gula darah dari 1 jam sebelum pembedahan ke 4 jam setelah pembedahan (Tabel 8). Frekuensi tertinggi kadar gula darah yang meningkat idalah pada anestesia umum dengan rerata 96 $\mathrm{mg} / \mathrm{dl}$ sedangkan rerata anestesi spinal 79,4 $\mathrm{mg} / \mathrm{dl}$. Penelitian yang dilakukan Manafi et al. ${ }^{10}$ terhadap pembedahan sesar menunjukkan hasil yang sama, yakni terdapat perbedaan bermakna antara anestesia spinal dan anestesia umum dengan rerata kadar gula darah setelah pembedahan dengan anestesia spinal 79,93 $\mathrm{mg} / \mathrm{dl}$ sedangkan pada anestesia umum 94,87 mg/dl. Hanya pada 1 pasien kadar gulanya tidak berubah yaitu pasien bedah minor dengan durasi pembedahan kurang dari 1 jam. Yang lainnya merupakan pembedahan mayor, antara lain caesarean section, dilatation and curettage, laparotomi, tonsilektomi, sinusektomi, open reduction internal fixation (ORIF), eksisi fibroadenoma mammae, ekstraksi corpus alienum, uretero renoscopy $(\mathrm{URS})+$ retrograde pielografi $(\mathrm{RPG})+$ litotripsi.

Banyaknya pasien yang mengalami peningkatan kadar gula darah setelah pembedahan berkaitan dengan peningkatan sekresi kortisol sejak dimulainya tindakan anestesi dan pembedahan yang dapat mencapai kadar puncak antara jam ke-3 sampai jam ke-6. Dan berdasarkan jenis pembedaahan serta teknik anestesia, kadar kortisol akan tetap meningkat bahkan dapat melebihi batasan normal, tapi cenderung menurun mendekati 24 jam terhitung sejak pembedahan dimulai. ${ }^{4,13}$

Berdasarkan jenis anestesia, anestesia umum lebih berpengaruh terhadap peningkatan kadar gula darah setelah pembedahan dibandingkan anestesia spinal (lihat tabel $7 \quad \&$ tabel 8). Terdapat perbedaan yang bermakna berdasarkan uji statistik karena nilai $\mathrm{p}<0,05$. Hasil penelitian ini didukung oleh penelitian Singh $\mathrm{M}^{4}$ mengenai Stress Response And Anaesthesia: altering the peri and postoperative management, yaitu anestesia spinal lebih berpengaruh langsung terhadap perubahan hormonal sebagai respon terhadap pembedahan dibandingkan dengan anestesia umum.

Pada anestesia umum, agen-agen intravena dan inhalasi yang digunakan dalam dosis normal hanya memiliki sedikit pengaruh terhadap fungsi endokrin dan metabolik, dalam hal ini yaitu perubahan 
hormonal yang terjadi sebagai akibat dari respon stres sehingga dapat meningkatkan sekresi kortisol dan menyebabkan peningkatan kadar gula darah, sedangkan anestesia spinal (subarachnoid block) memiliki pengaruh langsung terhadap fungsi endokrin dan metabolik, yakni menghambat sinyal nosiseptif mencapai sistem saraf pusat. Penghambatan terjadi pada impuls saraf aferen dan eferen dimana saraf aferenlah yang akan melepaskan kortisol melalui impuls saraf eferen oleh ACTH. Blokade pada dermatom L3-L4 atau L4-L5 dapat mengurangi peningkatan kortisol sehingga kadar gula darah setelah pembedahan tidak terlalu meningkat dibandingkan dengan anestesia umum. ${ }^{4}$

\section{SIMPULAN}

Berdasarkan hasil penelitian dan bahasan dapat disimpulkan bahwa anestesia umum lebih berpengaruh terhadap peningkatan kadar gula darah pasca pembedahan dengan rerata $96 \mathrm{mg} / \mathrm{dl}$ dibandingkan dengan anestesia spinal dengan rerata 79,4 mg/dl. Didapatkan perbedaan yang bermakna antara kadar gula darah pasca pembedahan dengan anestesia umum dan anestesia spinal $(\mathrm{p}=$ $0,006)$ atau $\mathrm{p}<0,05)$.

\section{SARAN}

Untuk peneliti selanjutnya diharapkan untuk membandingkan kadar gula darah terhadap satu jenis pembedahan yang bisa menggunakan anestesia umum dan anestesia spinal, misalnya pembedahan ortopedi.

\section{DAFTAR PUSTAKA}

1. Miller RD. Miller's Anesthesia Volume 2 (7th ed).. New York: Churchill Livingstone, 2010; p. 2940-42.

2. Desborough JP. The stress response to trauma and surgery. $\mathrm{Br} \mathrm{J}$ Anaesth. 2000;85:109-17.

3. Amiri F, Ghomeishi A, Aslani SM, Neisoonpour S, Adarvishi S. Comparison of surgical stress responses during spinal and general anesthesia in curettage surgery. Anesthesiology and Pain Medicine. 2014;4(3):e20554.

4. Singh M. Stress response and anesthesia: altering the peri and post-operative management. Indian J. Anaesth. 2003;47(6):427-34.

5. Mangku G, Senapathi TGA. Buku Ajar Ilmu Anestesia dan Reanimasi. Jakarta Barat: Indeks, 2010; P. 101.

6. Press CD. General anesthesia. 30 November 2015. [8 September 2015]. Available from:http://emedicine.medscape.com/ar ticle/1271543-overview

7. Salinas FV. Spinal anesthesia. Gravlee GP editor. A practical approach to regional anesthesia (4th ed). Philadelphia: Lippincott Williams and Wilkins, 2009; p. 60.

8. Press CD. Subarachnoid spinal block. 30 November 2015. [9 September 2015]. Tersedia di:http://emedicine.medscape.com/artic le/2000841-overview

9. Bernadus JE, Witjaksono, Soenarjo. Pengaruh induksi dengan propofol dan etomidat terhadap kadar gula darah. Jurnal Anestesiologi Indonesia. 2011;3:2.

10. Manafi A, Zakeri H, Salahyan F, Tavassoli M, Shekoohi F, Kokabi R, dkk. Blood glucose alterations in spinal anesthesia versus general anestesia in those undergoing caesarean section. Fasa University of Medical Sciences. 2015;5:44-50.

11. DHS. Anestesi spinal menurunkan risiko hiperglikemia pasca-operasi transplantasi panggul. Desember 2014 [6 September 2015]. Available from: http://www.kalbemed.com/Portals/6/28 _223Berita\%20Terkini-

Anestesi\%20Spinal\%20Menurunkan\% 20Risiko\%20Hiperglikemia\%20PascaOperasi\%20Transplantasi\%20Panggul. pdf

12. Topp DS. The nondiabetic's blood glucose tolerance to the stress or surgery. American Association of Nurse Anesthetists.338-41.

13. Purnama N, Sony, Fridayenti. Gambaran kadar gula darah perioperatif pada pasien bedah elektif menggunakan anestesi umum di rsud arifin achmad Provinsi Riau [Skripsi]. Riau: Fakultas Kedokteran Universitas Riau; 2013. 